https://doi.org/10.31713/m1013

\title{
CONTROL OF THE VIBRATION SPECTRUM IN SOILS AND ROCKS BASED ON THE MATHEMATICAL SIMULATION OF SHORT-RELEASED EXPLOSIONS
}

\author{
Remez N.S.
}

National Technical University of Ukraine "Igor Sikorsky Kyiv Polytechnic Institute", Doctor of Technical Sciences, Professor of the Department of Geoengineering, Ukraine

Boiko V.V.

Institute of Hydromechanics of the National Academy of

Sciences of Ukraine

Research laboratory on seismic safety of technological

explosions, Doctor of Technical Sciences, Professor, Head of the laboratory, Ukraine

\section{Dychko A.O.}

National Technical University of Ukraine "Igor Sikorsky Kyiv Polytechnic Institute", Doctor of Technical Sciences, Professor of the Department of Geoengineering, Ukraine

\section{Hrebeniuk T.V.}

National Technical University of Ukraine "Igor Sikorsky Kyiv Polytechnic Institute", Candidate of Technical Sciences, Associate Professor of the Department of Geoengineering, Ukraine

\section{Bronytskyi V.O.}

National Technical University of Ukraine "Igor Sikorsky Kyiv Polytechnic Institute", TF of the Department of Geoengineering, Ukraine

\section{Abstract}

In this work, seismic-explosive waves are investigated on the basis of mathematical simulation of short-delayed explosion of a system of charges and effective and seismic-safe schemes are calculated. Numerical simulation of the explosion of a group of charges of cylindrical symmetry in a rock mass is carried out. During the development of the explosion, two stages are distinguished. At the first stage, the explosion of a cylindrical explosive charge in an unlimited soil mass is considered. The principle of superposition of fields is used in the study of explosions of two or more charges, while the influence of the intervals of deceleration and distribution of masses of charges within a group on the parameters of seismic-explosion waves is investigated. It is established that approximately the same stress state is achieved in the soil mass in the near and middle zones of the 
explosion, which is necessary for the destruction of the rock. The efficiency of application of the proposed schemes for mining in quarries is proved. At the second stage of solving the problem, an assessment of the total action of a short-delayed explosion of a system of cylindrical charges is made.

The results of theoretical studies on the determination of the optimal short-delay detonation schemes depending on the distribution of masses within the group and the deceleration intervals are presented. The development of the method for calculating seismic vibrations based on mathematical modeling of a short-delayed explosion of a system of charges, which makes it possible to calculate wave parameters depending on the distribution of masses of charges within a group of deceleration intervals, is made and proved its effectiveness.

Keywords: explosion, short-delayed blasting, deceleration interval, vibration spectrum.

\section{Introduction}

Under conditions of the constantly expanding scale of blasting operations for the needs of the national economy, it is necessary to develop new approaches to their implementation, in which it is possible to achieve both effective destruction of rocks and ensure seismic safety of protected objects. If, relatively recently, explosive technologies were used only for crushing or mining of rocky rocks, nowadays, explosive methods are gaining importance in the extraction of natural hydrocarbons, the construction of engineering structures in rocks, soil compaction, strengthening, stamping and welding of metals, etc. Variety of technological operations using the energy of the explosion is determined both by the possibility of creating high pressures and by the speed of the operating of working processes. However, along with the advantages, blasting operations have a significant disadvantage - low efficiency of the explosion (when crushing rocks, it does not exceed 10\%, when stamping $15 \ldots 18 \%$ ). As a result of the action of seismic and explosive loads from blasting operations, there is a disturbance and decrease of the rock mass outside the contour of the blasted area. As a result, the cohesion of rocks decreases, while the friction forces on weakened surfaces are significantly reduced, which can ultimately lead to catastrophic consequences.

A large number of studies by Ukrainian and foreign scientists are devoted to the mechanics of surface manifestation of seismic effects, but the most number of publications concerns earthquakes. The influence of the amplitude-frequency characteristics of oscillations during man-made 
explosions on the foundations of protected objects, despite the expanding scope of blasting operations, is not studied sufficiently. In practice, the assessment of the impact of seismic explosive waves on protected objects is carried out on the basis of the existing regulatory documentation only for the parameter of the permissible mass vibration velocity, without taking into account the frequency characteristics in the system, which leads to a significant error in assessing the intensity of seismic vibrations during explosions.

Studies [1-6] cannot solve the problem of optimal prediction of the seismic effect of industrial explosions, since they are based on the laws of vibration propagation during the explosion of a concentrated charge, which leads to a discrepancy between the calculated and actual data. In [7, 8], the interaction of blast waves during short-delayed blasting is studied, but the amplitude-frequency characteristics of seismic vibrations are not taken into account.

The purpose of the work - is investigation of seismic explosive waves on the basis of mathematical simulation of short-delay explosion of a system of charges for the calculation of effective and seismic-safe schemes.

\section{Material and research results}

In this work, a numerical simulation of the effect of an explosion of a group of charges of cylindrical symmetry in a rock mass is carried out, while two stages are distinguished at the development of an explosion.

At the first stage, the explosion of a cylindrical explosive charge (HE) in an unlimited soil massif is considered. The movement of detonation products and soil is described by equations (1)-(5).

The problem is solved in a related formulation, while it is assumed that in the rock mass far from the free surface there is a cylindrical explosive charge (HE) with a length $l$ and radius $r_{0}$, which detonates instantly. As a result of the instantaneous action of this pressure on the contact boundary of the "detonation products - rock" section, a shock wave is spread through the massif, the contact boundary expands, and a converging wave moves to the charge axis. In this case, an equally high pressure $P_{n}$ is established throughout the entire volume of the charge. And the density of detonation products (DP) $\rho_{n}$ is equal to the initial density of the explosive. 
Detonation products and rock (HP) are studied within the framework of continuum mechanics, the equations of motion for cylindrical symmetry are as follows [9]

$$
\begin{gathered}
\frac{\partial \sigma_{r r}}{\partial z}+\frac{\partial \sigma_{r z}}{\partial r}+\frac{\tau_{r z}}{r}=\rho \frac{d u}{d t}, \quad u=\frac{d z}{d t} ; \\
\frac{\partial \tau_{r z}}{\partial z}+\frac{\partial \sigma_{z z}}{\partial r}+\frac{\sigma_{z z}-\sigma_{\theta \theta}}{r}=\rho \frac{d w}{d t}, \quad w=\frac{d r}{d t} ; \\
\frac{1}{V} \frac{d V}{d t}=\frac{\partial u}{\partial z}+\frac{\partial W}{\partial r}+\frac{W}{r} \\
\sigma_{z z}=S_{z z}-P ; \quad \sigma_{r r}=S_{r r}-P ; \quad \sigma_{\theta \theta}=S_{\theta \theta}-P \\
P=\frac{1}{3\left(\sigma_{r r}+\sigma_{\theta \theta}+\sigma_{z z}\right)} ; \quad V=\frac{\rho_{0}}{\rho} ;
\end{gathered}
$$

where $z, r$ - coordinates;

$t$ - time;

$\sigma_{r r}, \sigma_{\theta \theta}, \sigma_{z z}$ - normal voltages;

$\tau_{z r}$ - shear stress;

$S_{z z}, S_{r r}, S_{\theta \theta}$ - stress tensor deviator components,

$P$ - mean hydrostatic pressure;

$\rho$ - density;

$u, w$-velocity components;

$V$ - specific volume.

The expansion of detonation products occurs according to the two-term isentrope

$$
P=A \times \rho^{n}+B \rho^{\gamma+1},
$$

where $A, B, n, \rho$ - constants that characterize this type of explosive. The initial conditions of the problem are as follows

$$
\begin{aligned}
& u=0, w=0, P=P_{n} \rho=\rho_{n} \text { at } \quad z<l, r<r_{0} \\
& u=0, w=0, P=P_{0} \rho=\rho_{0} \text { at } \quad z<l, r<r_{0}
\end{aligned}
$$

The boundary conditions are as follows

$$
\begin{aligned}
& u_{d p}=u_{s}, \quad P_{d p}=P_{s}, \quad \rho_{d p} \neq \rho_{s} \quad \text { at } \quad z=1 \\
& w_{d p}=w_{s}, \quad P_{d p}=P_{s}, \quad \rho_{d p} \neq \rho_{s} \quad \text { at } \quad r=r_{0}
\end{aligned}
$$

Here, the indices "DP" and "S" mean detonation products and soil, respectively. 
When investigating explosions of two or more charges, the principle of superposition is used.

To approximate the system of differential equations (1)-(10), the method of finite differences is used using a finite-difference scheme of the "cross" type [10] of the second order of accuracy in spatial and temporal coordinates.

The influence of the intervals of deceleration and distribution of masses of charges within the group on the parameters of seismicexplosive waves is investigated. In this case, it is assumed that the same group mass explodes, but according to different schemes. In the case of three charges, according to the first scheme, at first a charge of a smaller mass explodes, then a larger one, and, finally, a smaller one, equal to the mass of the first charge. Let's call this pattern "triangle up". According to the second scheme, a charge of a larger mass explodes, then a smaller one, and again a larger one ("triangle down"). With an increase in the number of charges, such a mass distribution is maintained according to the two proposed schemes (Fig. 1).

$a$

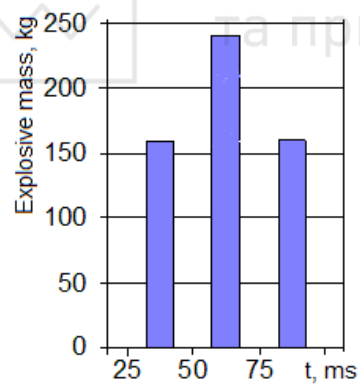

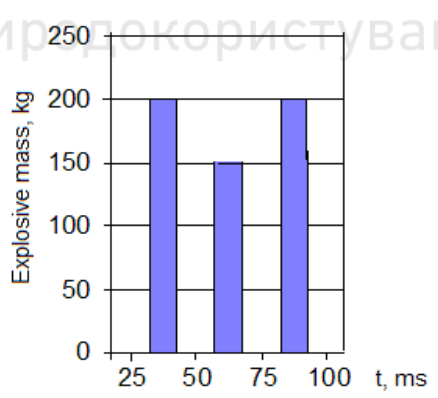

Fig. 1. Various schemes of exploding a group of cylindrical charges: $a$ - "triangle up", $b$ - "triangle down"

The explosion of a system of cylindrical charges of TNT in loam with a deceleration interval $\Delta t=0,02 \mathrm{~s}$ is studied. The physical and mechanical characteristics of the loess are as follows: $\rho_{10}=1,2$, $\rho_{20}=1000, \rho_{30}=2650 \mathrm{~kg} / \mathrm{m}^{3} ; c_{10}=330, \quad c_{20}=1500, \quad c_{30}=4500 \mathrm{~m} / \mathrm{s}$, $\gamma_{1}=1,4, \gamma_{2}=7, \gamma_{3}=4$.

The explosive used is TNT with an initial density of $\rho_{m}=1600$ $\mathrm{kg} / \mathrm{m}^{3}$, which constants for the equation of state (6) have the 
following values: $P_{n}=9,6 \cdot 10^{9} \mathrm{~Pa} ; k_{n}=3, k_{0}=1,25, n=3,123, \gamma=1,25$, $A=0,884 \mathrm{~Pa}\left(\mathrm{~kg} / \mathrm{m}^{3}\right)^{-\mathrm{m}}, B=0,623 \cdot 10^{5} \mathrm{~Pa}\left(\mathrm{~kg} / \mathrm{m}^{3}\right)^{-\gamma}$.

Various variants of mass distribution are investigated. Let's take the mass $36,0 \mathrm{~kg}$ as a unit charge $q$. Then, in the first version of calculations according to the first scheme, the masses of sequentially exploded charges are as follows $Q_{1}=q, Q_{2}=1,4 q, Q_{3}=q$; to the second one - $Q_{1}=1,2 q, Q_{2}=q, Q_{3}=1,2 q$.

Fig. 2 and 3 show the isobars of voltages $\sigma_{r r}$ (in $10^{-3} \mathrm{~Pa}$ ) at the moment of time $t=40 \mathrm{~ms}$ for short-delayed explosions of the system of cylindrical charges, produced according to the "triangle up" and "triangle down" schemes. From the analysis of the figures, it follows that in the soil massif in the near and middle zones of the explosion, approximately the same stress state is achieved, which is necessary for the destruction of the rock. Therefore, we can conclude about the effectiveness of the application of both schemes for the extraction of minerals in open quarries.

At the second stage of solving the problem, the dependences of the maximum displacement on the relative distance $r_{i}$ during the explosion of the i-th cylindrical charge with mass $Q_{i}$ are used, obtained as a result of a numerical solution in the form

$$
\left(u_{\max }\right)_{i}=k\left(\frac{Q_{i}}{r_{i}}\right)^{\mu}
$$

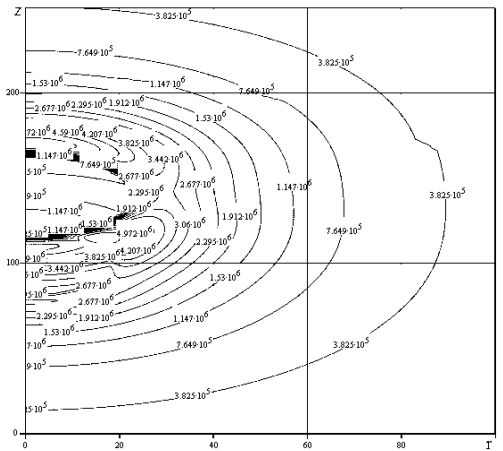

Fig. 2. Isobars of voltages $\sigma_{r r}$ (in Pa) at the moment $t=40 \mathrm{~ms}$ of the explosion of cylindrical charges according to the "triangle up" scheme

To estimate the total action of a short-delayed explosion of a system of cylindrical charges, the principle of superposition of waves 
is used [9]. The disturbance in the elastic zone for the $i$-th source can be described by the following expression

$$
u_{i}=\left(u_{\max }\right)_{i} e^{-v t} \sin w_{i} t,
$$

where $\left(u_{\max }\right)_{i}$ - maximum displacement amplitude for the $i$-th charge, $v$ - seismic wave attenuation index, $\omega_{i}$ - oscillation frequency from the $i$-th source.

Then the resulting displacement in a short-delayed explosion of $n$ different charges with deceleration interval $\Delta t$ is determined by the formula $u=\sum_{i=1}^{n} u_{i}$, or, taking into account formulas (11-12), we obtain the expression

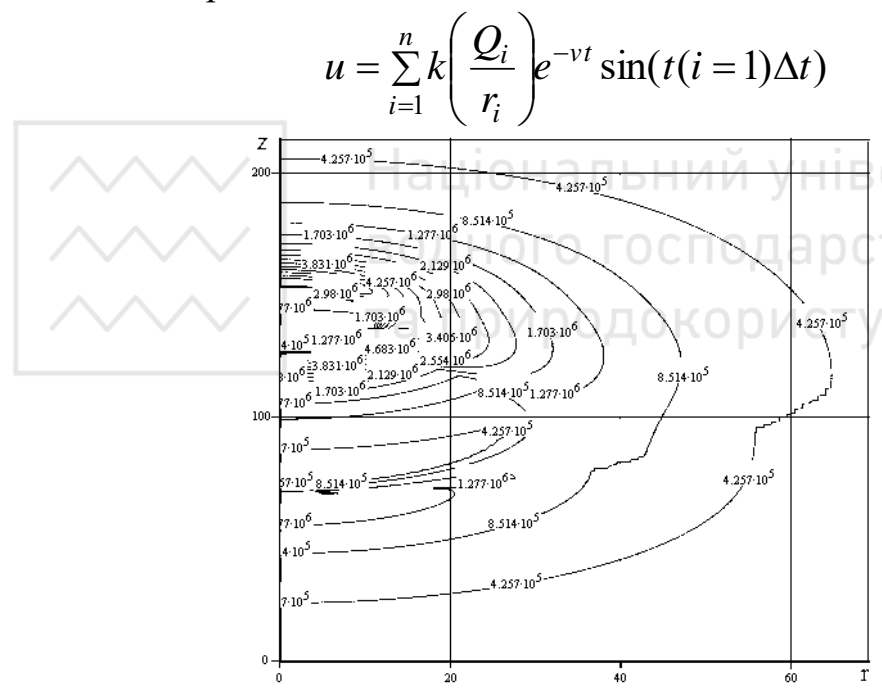

Fig. 3. Isobars of voltages $\sigma_{r r}$ (in Pa) at the moment $t=40 \mathrm{~ms}$ of the explosion of cylindrical charges according to the "triangle down" scheme

Let us consider the explosions of a system of cylindrical charges of TNT in loam with an interval of deceleration $\Delta t=0,02 \mathrm{~s}$. The total weight of the group is $112,4 \mathrm{~kg}$. Various variants of mass distribution are investigated. For convenience of presentation, we denote the charge by the mass $Q_{1}=36,0 \mathrm{~kg}$ per unit charge $q$. Then, in the first version, according to the first scheme, the masses of sequentially 
exploded charges are as follows $Q_{1}=q, Q_{2}=1,4 q, Q_{3}=q$; on the second $-Q_{1}=1,2 q, Q_{2}=1,2 q, Q_{3}=1,2 q$.

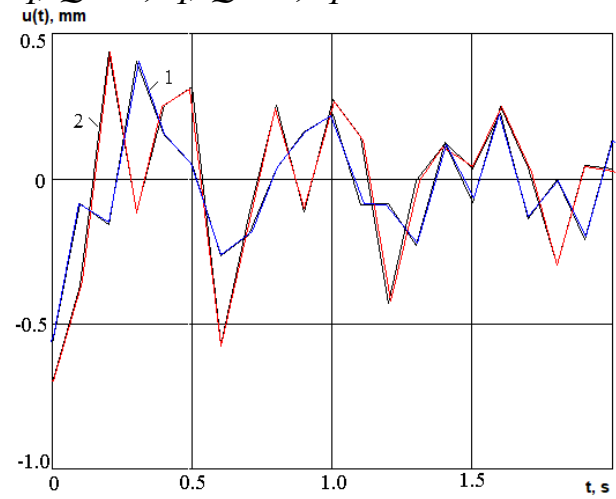

Fig. 4. Dependences of the displacement on time at a distance of $1000 \mathrm{~m}$ from the epicenter of the explosions: 1 - $Q_{1}=1,2 q, Q_{2}=1,2 q, Q_{3}=1,2 q ; 2-Q_{1}=1,2 q, Q_{2}=q, Q_{3}=1,2 q$

Fig. 4 shows the time dependences of the displacement at a distance of $1000 \mathrm{~m}$ from the epicenter of the explosions. The numbering of the curves corresponds to the numbering of the proposed detonation schemes.

From the analysis of the figure it follows that with a slight difference in the displacement amplitudes, the frequency of oscillations during detonation of charges according to the second scheme is twice higher than according to the first, which is an unfavorable factor for the seismic resistance of protected objects.

The following variants of blasting schemes are investigated. In the second variant according to the first scheme $Q_{1}=0,9 q, Q_{2}=1,6 q$, $Q_{3}=0,9 q$; to the second one - $Q_{1}=1,4 q, Q_{2}=0,6 q, Q_{3}=1,4 q$ (Fig. 5).

In the third version according to the first scheme, the masses $Q_{1}=1,1 q, Q_{2}=1,2 q, Q_{3}=1,1 q$; to the second one - $Q_{1}=1,2 q, Q_{2}=q$, $Q_{3}=1,2 q$ (Fig. 6). 


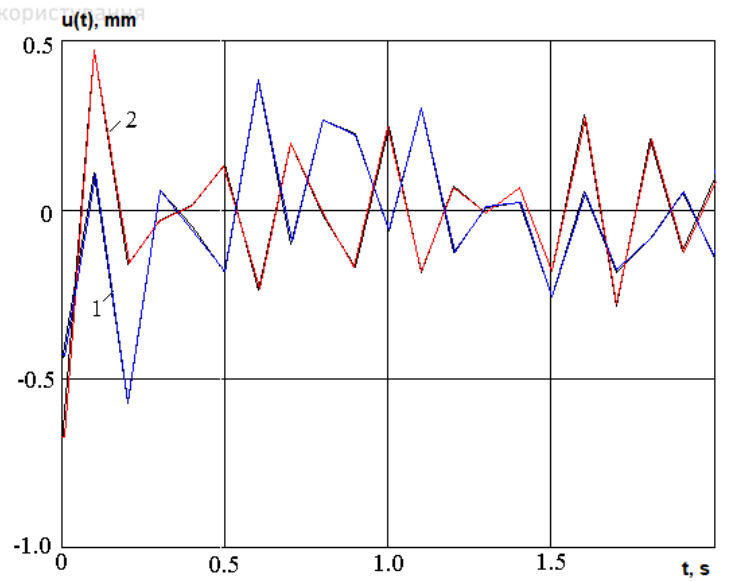

Fig. 5. Dependences of displacement in time at a distance of $1000 \mathrm{~m}$ from the epicenter of explosions at various blasting schemes: $1-Q_{1}=0,9 q, Q_{2}=1,6 q$, $Q_{3}=0,9 q ; 2-Q_{1}=1,4 q, Q_{2}=0,6 q, Q_{3}=1,4 q$

From the Fig. 4 it follows that with an increase in the difference in the masses of successively detonated charges in comparison with the first option, with a slight increase in the amplitude of oscillations, a significant increase in frequency occurs in both detonation schemes (1,5 times).

A decrease in the difference in charge masses (Fig. 6) does not lead to an increase in the vibration frequency compared to the first option, but leads to an increase in the amplitude at $20-25 \%$, which also undesirably affects on the seismic resistance of protected objects.

From the analysis of Figures 4-6 it follows that for any mass distribution in the group, the "triangle up" circuits are preferable to the "triangle down" circuits because the first ones generate lower vibration frequencies.

In addition, it is found that for a specific group mass of charges and soil conditions, there is an optimal distribution of masses within the group, in our case it is scheme 1 according to the first option: a "triangle up" scheme with a mass difference of $40 \%$. 


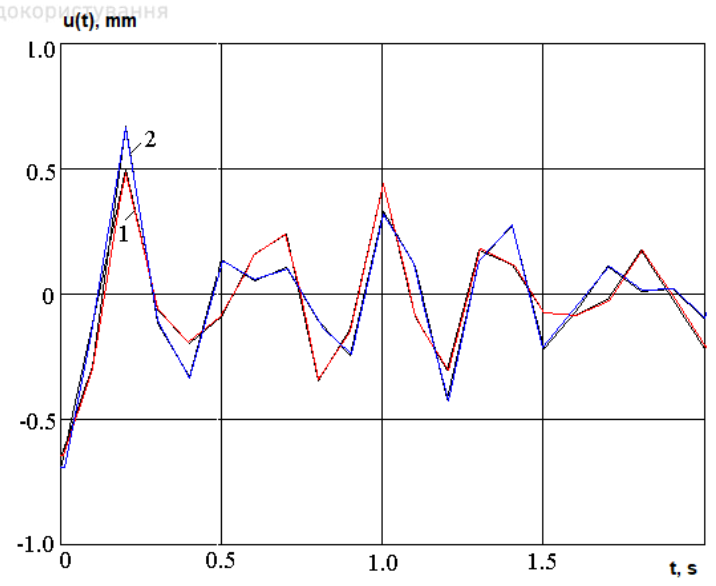

Fig.6. Dependences of displacement in time at a distance of $1000 \mathrm{~m}$ from the epicenter of explosions at various blasting schemes: $1-Q_{1}=1,1 q, Q_{2}=1,2 q, Q_{3}=1,1 q$; 2 - $Q_{1}=1,2 q, Q_{2}=q, Q_{3}=1,2 q$

It should be noted that the study of explosions of the group of 4 and 5 charges obtained results are similar to those described above.

Figure 7 shows the time dependences of the displacement at a distance of $1000 \mathrm{~m}$ from the epicenter of explosions in explosions of a group of four charges with different mass distributions. According to the first explosion scheme $Q_{1}=0,5 q, Q_{2}=1,2 q, Q_{3}=1,2 q, Q_{4}=0,5 q$; to the second one $-Q_{1}=1,2 q, Q_{2}=0,5 q, Q_{3}=0,5 q, Q_{4}=1,2 q$.

From the comparing Fig. 6 with Fig. $4-5$ it follows that with the dispersal of the explosive mass (an increase in the number of charges), the frequency of oscillations during explosions according to the "triangle up" scheme decreases. At the same time, during explosions according to the second scheme, the amplitude increases in 1.5 times and the frequency - in 1.7 times. 


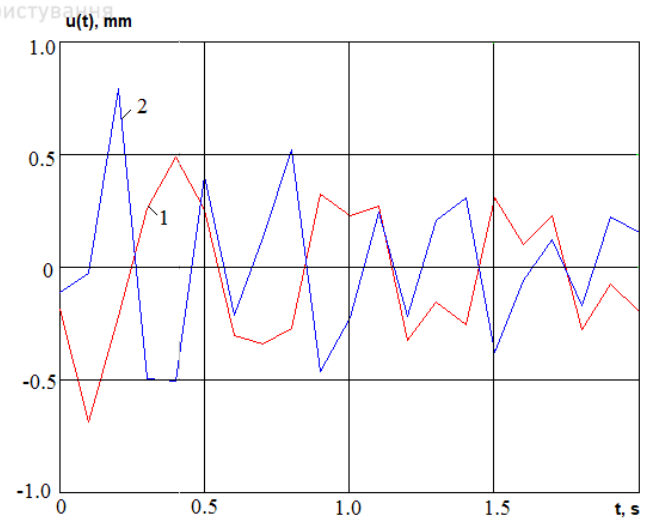

Fig.7. Dependences of displacement on time at a distance of $1000 \mathrm{~m}$ from the epicenter of explosions at various blasting schemes: $1-Q_{1}=0,5 q, Q_{2}=1,2 q, Q_{3}=1,2 q$, $Q_{4}=0,5 q ; 2-Q_{1}=1,2 q, Q_{2}=0,5 q, Q_{3}=0,5 q, Q_{4}=1,2 q$

The study of the effect of a further increase in the number of charges on the frequency-amplitude spectrum of oscillations is made. From the comparison of Fig. 7 and 8 , it can be concluded that a further increase in the number of charges with the same total mass in the group leads to a significant decrease in the amplitude-frequency spectrum of ground vibrations. But just as for the cases considered above, the "triangle up" scheme gives lower values of the amplitude (2 times) and frequency (1,3 times) compared to the "triangle down" scheme).

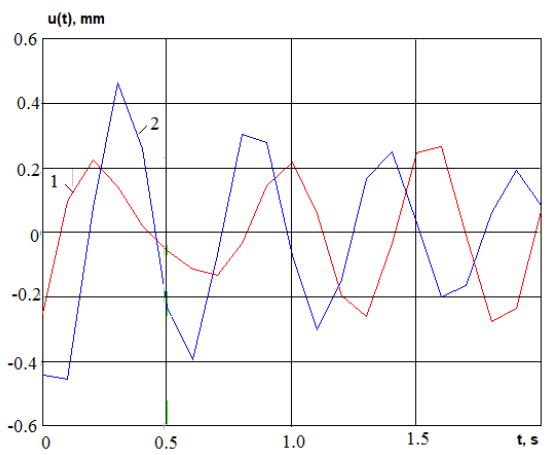

Fig. 8. Dependences of displacement in time at a distance of $1000 \mathrm{~m}$ from the epicenter of explosions at various blasting schemes: $1-Q_{1}=0,5 q, Q_{2}=1,7 q, Q_{3}=1,0 q$, $Q_{4}=0,7 q ; 2-Q_{1}=0,85 q, Q_{2}=0,7 q, Q_{3}=0,5 q, Q_{4}=0,7 q$ 
To study the influence of the deceleration intervals on the spectrum of seismic vibrations, studies of group explosions are carried out according to the 1 st option, 1 scheme. Figure 9 shows the time dependences of the displacement for different deceleration intervals: curve 1 corresponds to $\Delta t=0,02 \mathrm{~s}, 2-\Delta t=0,04 \mathrm{~s}, 3-$ $\Delta t=0,065 \mathrm{~s}$.

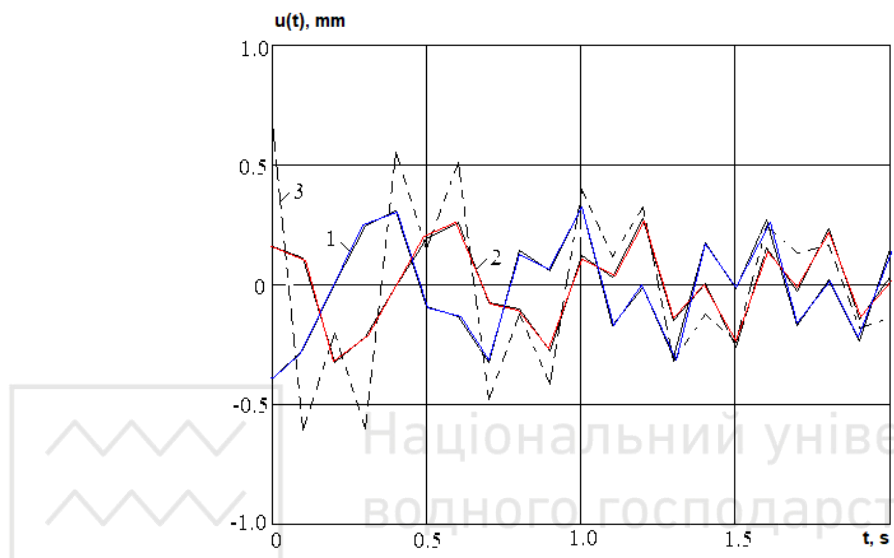

Fig. 9. - Dependences of the displacement in time at a distance of $1000 \mathrm{~m}$ from the epicenter of the explosions: $1-\Delta t=0,02 \mathrm{~s} ; 2-\Delta t=0,04 \mathrm{~s} ; 3-\Delta t=0,065 \mathrm{~s}$

It is shown in the Figure 9 that with a twice increase in the deceleration interval (curves 1 and 2, respectively), the amplitude and frequency of oscillations decreases, which is quite an expected result. However, with a further increase in the deceleration interval (curve 3), a significant increase in the amplitude and frequency of seismic vibrations occurs, which is undesirable for protected objects. From this analysis, it follows that there is an optimal most safe deceleration interval for group explosions.

\section{Conclusions}

An effective method of calculating seismic vibrations based on mathematical modeling of short-delayed explosion of a system of charges, allowing the calculation of wave parameters depending on the distribution of charge masses within a group of deceleration intervals, is developed.

On the basis of numerical and analytical studies, it is established that there are optimal blasting schemes (for the studied conditions - 
"triangle up" with a mass difference of 40\%) and optimal periods of deceleration from the point of view of seismic safety of protected objects.

The direction of further research is the study of the influence of soil conditions, parameters of charges and their mutual arrangement on the spectral characteristics of seismic vibrations.

The results of this work can be used in the design of blasting operations for the calculation of rational blasting schemes and control of the explosive spectrum of vibrations.

References

1. Sadovskiy M.A. Seysmicheskiy effekt vzryiva. Tr. Vses. sovesch. po burovzryivnyim rabotam. M.-L., Gostopizdat, 1940, s. 290-319.

2. Bogatskiy V. F., Fridman A. G. Ohrana inzhenernyih sooruzheniy i okruzhayuschey sredyi ot vrednogo deystviya promyishlennyih vzryivov - M. : Nedra, 1982. $-162 \mathrm{~s}$.

3. Mironov P. S. Vzryivyi i seysmobezopasnosnost sooruzheniy - M.: Nedra, 1973. $-168 \mathrm{~s}$.

4. Safonov L. V., Kuznetsov G. V. Seysmicheskiy effekt vzryiva skvazhinnyih zaryadov - M. : Nauka, 1967. - $102 \mathrm{~s}$.

5. Tseytlin Ya.I., Smoliy N.I. Seysmicheskie i udarnyie vozdushnyie volnyi promyishlennyih vzryivov. - M.: Nedra, 1981, -192 s.

6. Kuzmenko A.A., Vorobev V.D. Obespechenie bezopasnogo vzryivaniya v karerah stroitelnyih materialov. Institut gidromehaniki AN Ukrainyi.-Kiev, 1992.24s.- DEP v UkrINTEI 11.08.1992 g., №1192-UK92.

7. Melnik G.V. Regulirovanie spektra seysmokolebaniy pri korotkozamedlennom vzryivanii. - Vzryivnoe delo. - M.: Nedra, 1983. - S.48-52.

8. Lyashenko V.I., Melnik G.V., Shvyidko P.V. Progresivnyie tehnologii upravleniya vzryivnyimi rabotami na gornyih predpriyatiyah. Tsvetnaya metallurgiya. Gornoe delo - M. - 2009. - №8 - S. 3-11.

9. Luchko I.A., Plaksiy V.A., Remez N.S. i dr. Mehanicheskiy effekt vzryiva v gruntah - Kiev: Nauk. dumka, 1989. - $232 \mathrm{~s}$.

10. Luchko I.A., Remez N.S., Luchko A.I. Matematychne modeliuvannia dii vybukhu i gruntakh i hirskykh porodakh. Kyiv: NTUU «KPI», - 2011. - 264 s. 